\title{
COMPETITIVIDAD DEL SECTOR TRANSPORTE INTERMUNICIPAL DE PASAJEROS EN BOYACÁ ${ }^{1}$
}

\author{
COMPETITIVENESS OF MUNICIPAL PASSENGERS TRANSPORTATION SECTOR \\ IN BOYACÁ
}

\section{Diego Armando Rodríguez Álvarez ${ }^{2}$ Claudia Jessenia Becerra Gualdrón ${ }^{3}$}

Para citar este artículo: Rodrígues, D. y Becerra, C. (2014). “Competitividad del sector transporte intermunicipal de pasajeros en Boyacá”. Inquietud Empresarial. Vol. XIV (2), p.p. 33-67

1 Artículo de investigación científica y tecnológica como resultado del proyecto de investigación titulado "Análisis de las brechas competitivas del sector transporte intermunicipal de pasajeros en el departamento de Boyacá".

2 Administrador de Empresas UPTC. Estudiante de Maestría en Administración de Organizaciones UPTC. Investigador Grupo de Investigación CREPIB. diego.rodriguez@ crepib.org.co

3 Economista UPTC. Estudiante de Maestría en Economía UPTC. Investigadora Grupo de Investigación CREPIB. claudia.becerra@crepib.org.co 


\section{RESUMEN}

El sector de transporte de pasajeros, al igual que otros sectores de la economía nacional, actualmente registra una serie de problemas relacionados con competitividad. Por lo anterior, instituciones como la ANDI, en el Tercer Congreso Nacional de Transporte de Pasajeros, identifica las siguientes problemáticas en el sector: No hay Homogeneidad en servicio de transporte, existencia de prelación de precios y deficiente control por parte del estado. La informalidad en el transporte de pasajeros, constituye una amenaza, debido a que no se garantiza al pasajero un buen servicio, las empresas formales, dejan de percibir utilidades, por tanto es difícil invertir, innovar y crecer. En consecuencia, el sector no puede crear, ni mantener ventajas competitivas. De seguir presentándose las situaciones, anteriormente mencionadas, el sector de transporte intermunicipal de pasajeros, no logrará niveles de competitividad tendientes a garantizar calidad, innovación y productividad. Teniendo en cuenta la problemática descrita, surge el interés de realizar un análisis detallado de brechas competitivas en el sector transporte intermunicipal de pasajeros en Boyacá, que permita vislumbrar estrategias que garanticen la sostenibilidad de las empresas, teniendo en cuenta las exigencias y tendencias del mercado.

\section{PALABRAS CLAVE}

Competitividad, transporte, tendencias, calidad, servicio, cliente, entorno

\section{ABSTRACT}

The passenger transport sector, like other sectors of the national economy is currently making a series of issues related to competitiveness. Therefore, institutions as ANDI, in the Third National Congress of Passenger Transport, identifies the following problems in the sector: Homogeneity No shuttle service, existence of predatory pricing and poor control by the state. Informality in the passenger is a threat because the passenger is not guaranteed good service, formal firms, foregone earnings, so it is difficult to invest, innovate and grow. Therefore, the sector cannot create or maintain competitive advantage and therefore there is no competition. To continue presenting the situations above, the inter-sector passenger transport, not achieve competitive levels designed to ensure quality, innovation and productivity. Given the problems described, there is the interest of a detailed competitive gaps in inter passenger sector in Boyacá, allowing a glimpse of strategies to ensure the sustainability of enterprises, taking into account the requirements and market trends analysis .

\section{KEYWORDS}

Competitiveness, transportation, trends, quality, service, customer, environment

\section{INTRODUCCIÓN}

En el marco del proyecto "Análisis de las brechas competitivas en las empresas del sector transporte terrestre intermunicipal de pasajeros en el departamento de Boyacá", realizado por el Grupo de investigación Equipo CREPIB $^{4}$, de la Universidad Pedagógica y Tecnológica de Colombia UPTC, se establece como uno de los objetivos identificar las tendencias competitivas del sector del transporte terrestre intermunicipal de pasajeros a nivel mundial, nacional y local, con el fin de desarrollar una herramienta conducente a establecer un punto de partida para la identificación y análisis de brechas competitivas en las empresas del sector objeto de estudio en Boyacá, así como, facilitar el diseño de estrategias que permitan elevar

4 Centro Regional de Gestión para la Productividad y la Innovación de Boyacá 
el grado de sostenibilidad de las empresas.

Este documento consta de cinco partes: La primera parte contiene las generalidades de la competitividad y las diferentes teorías relacionadas con los modelos de análisis competitivo, la segunda parte hace referencia al estado actual de la competitividad en Colombia y Boyacá, como referente de análisis en el entorno del sector del transporte intermunicipal de pasajeros, la tercera parte, identifica los factores de competitividad en el sector de los servicios, teniendo en cuenta la naturaleza de la presente investigación, la cuarta parte, resume las tendencias competitivas a nivel mundial, nacional y departamental con relación al transporte de pasajeros y en la quinta parte, se presenta los resultados obtenidos en el estudio.

\section{Generalidades de la competitividad}

Los últimos años caracterizados por la globalización, han despertado en las empresas la necesidad de equipararse para afrontar las exigencias de un mercado competitivo a nivel mundial, más aún, cuando estas se encuentran localizadas en países en vía de desarrollo como Colombia. Por esta razón se puede afirmar que las organizaciones, deben revisar sus estrategias y políticas para lograr un nivel de competitividad, que les permita al menos sobrevivir y no decaer ante las grandes potencias que gozan de múltiples beneficios económicos representados en tecnologías avanzadas capaces de desarrollar productos y/o servicios a un bajo costo con mayor calidad, logrando adquirir un posicionamiento en el mercado global.

\subsection{Definición de competitividad}

Actualmente el término competitividad se aplica a una empresa, a un sector económico o a un país (Gónzalez, 2000), por tanto existen diferentes enfoques en cuanto su definición, debido a su aplicación en distintos entornos competitivos, por tal razón, es necesario conocer los conceptos teóricos de varios autores relacionados con el tema.

La competitividad se puede definir como: "un concepto que no tiene límites precisos y se define en relación con otros conceptos. La definición operativa de competitividad depende del punto de referencia del análisis -nación, sector, firma-, del tipo de producto analizado -bienes básicos, productos diferenciados, cadenas productivas, etapas de producción- y del objetivo de la indagación -corto o largo plazo, explotación de mercados, reconversión, etcétera” (Piñeiro y otros, 1993). Esta definición sustenta la esencia de los estudios de competitividad, los cuales deben partir de un referente de análisis que permita establecer los lineamientos objetivos en términos espaciales y de tiempo.

\section{Modelos teóricos de competitividad}

Con el fin de identificar una herramienta que permita un análisis crítico de la competitividad de un sector económico, en este caso el del transporte intermunicipal de pasajeros, es importante identificar modelos teóricos que aporten al estudio de las brechas competitividad, así mismo proporcionen un fundamento serio y coherente en el proceso analítico.

Actualmente existe diversidad de modelos tendientes a analizar la competitividad. Con el paso del tiempo se evidencian cambios estructurales en el entorno, situación que conlleva a que continuamente se generen nuevos modelos de análisis de competitivo; es así como las teorías de autores de hace algunas décadas, como es el caso de Porter, tienden a perder objetividad, dado que los escenarios son distintos con pasar del tiempo. Esta situación se refleja en cambios de gran magnitud en entorno como: La globalización, el calentamiento global, las nuevas tendencias 
de la tecnología, nuevos hábitos y preferencias en personas, entre otros aspectos incidentes en la sostenibilidad de las empresas.

Los modelos que se presentan a continuación establecen diferentes parámetros en el análisis de competitividad, el primero basado en la generación de ventajas competitivas derivadas en la interrelación de actores del entorno (Diamante de Porter). Así mismo se presenta un modelo causal basado en capacidades y recursos, el cual pretende comprobar la incidencia de un conjunto de variables en la competitividad, estableciendo la correlación en cada una de ellas. Por último el modelo sistémico propuesto por Klaus Esser, propone un estudio de análisis de incidencia de los factores en cada uno de los niveles del entorno (micro, meso, meta), en la competitividad de las empresas.

\subsection{Diamante de Porter}

Porter plantea un modelo a fin de determinar los efectos de la utilidad de un mercado a largo plazo, por medio de la evaluación de sus objetivos y recursos frente a cinco fuerzas que rigen la competitividad. Desarrolla el modelo del diamante de la competitividad donde relaciona cuatro fuentes de ventajas competitivas que se derivan de la ubicación de las empresas, sectores y sus interrelaciones. El modelo se ilustra en el siguiente gráfico.

Amenaza de entrada de nuevos competidores: La entrada de un nuevo competidor al mercado trae con sigo nuevas capacidades, un deseo de adquirir una porción del mercado y en algunas ocasiones ciertos recursos sustanciales, situación que conduce a ejercer presión sobre precios, costos e inversión requerida para competir, afectando la rentabilidad del sector.

Barreras de entrada: Las barreras de entrada son ventajas que tienen los actores establecidos en comparación con los nuevos entrantes. Existen siete fuentes importantes (Porter, 2008).

Economías de escala por el lado de la oferta. Estas economías aparecen cuando empresas que producen en grandes volúmenes cuyos costos son más bajos por unidad, pues pueden distribuir los costos fijos entre más unidades, disponer de tecnología más eficaz o exigir mejores condiciones de los proveedores. Las economías de escala por el lado de la oferta dificultan la entrada de nuevos competidores al obligar a los nuevos actores ingresar al sector en gran escala, lo que requiere desplazar a los competidores establecidos, o aceptar una desventaja de costos.

Beneficios de escala por el lado de la demanda. Este beneficio se relaciona con la confianza de los compradores hacia las empresas grandes reconocidas por un buen número compradores, lo cual refleja una ventaja competitiva relacionada con el posicionamiento empresarial.

Costos para los clientes por cambiar de proveedor. Cuando los compradores cambian de proveedor, deben asumir ciertos costos fijos, por ejemplo, el cambio de especificaciones del producto, volver a capacitar a los empleados respecto al uso del nuevo producto, entre otros que afectan la producción de bienes y servicios.

Requisitos de capital. El recurso financiero, puede constituir una barrera de entrada para impedir el ingreso de nuevos competidores, debido a la exigencia del mercado en altas inversiones para que una empresa pueda competir, teniendo en cuenta las exigencias de los consumidores, en términos de calidad e innovación.

Ventajas de los actores establecidos independientemente del tamaño. Independientemente de su tamaño, los actores establecidos tendrán ventajas 
relacionadas con la variable costos y calidad que no están al alcance de sus potenciales rivales.

Acceso desigual a los canales de distribución. Una de las preocupaciones cuando ingresa un nuevo producto o servicio al mercado está relacionada con la distribución. Mientras más limitados son los canales mayoristas o minoristas y mientras más copados los tienen los competidores existentes, más difícil será entrar en un sector

Políticas gubernamentales restrictivas. Las políticas del gobierno pueden obstaculizar o incentivar en forma directa la entrada de nuevos competidores a un sector, y también pueden extender (o eliminar) las otras barreras de entrada.

Poder de negociación de los proveedores: Los proveedores constituyen un factor primordial en la competitividad de las empresas, más aún, cuando estos tienen una amplia participación en el mercado, situación que permite capturar una mayor parte del valor para sí mismos cobrando precios más altos, restringiendo la calidad o los servicios, o transfiriendo los costos a los participantes del sector.

El poder de los compradores: Los clientes poderosos al lado inverso de los proveedores poderosos son capaces de capturar más valor si obligan a que los precios bajen, exigen mejor calidad o mejores servicios (lo que incrementa los costos) y, por lo general, hacen que los participantes del sector se enfrenten; todo esto en perjuicio de la rentabilidad del sector.

Productos sustitutos: los productos sustitutos limitan las posibilidades de un sector, debido a que generan un techo a los precios de venta que el sector pueda fijar.

\subsection{MODELO CAUSAL DE COMPETITIVIDAD BASADO EN LOS RECURSOS}

La Revista Investigaciones Europeas de Dirección y Economía de la Empresa, presenta un artículo, donde propone un modelo causal basado en los recursos, cuya finalidad es explicar la competitividad a partir de los factores internos de la empresa (Capacidades directivas, de innovación, de marketing y Calidad) (R Martínez, 2010).

Este modelo, permite responder a la pregunta ¿Por qué las empresas compiten en el mismo sector o industria y tienen rentabilidades diferentes?, para este interrogante, plantea dos premisas: 1. Las empresas son heterogéneas respecto a sus recursos estratégicos y su modo de uso o manejo y 2. Los recursos tienen problema en transferirse de una empresa a otra debido a los mercados en los que compiten son muy imperfectos o no existen. Por lo anterior, se infiere que son los recursos y capacidades de cada empresa y su adecuada gestión, los que permiten distinguirla de las demás, dando como resultado una ventaja competitiva, reflejando así niveles diferentes de rentabilidad de las empresas. Las capacidades están ligadas al recurso humano susceptible en la generación de ventajas competitivas, por tal razón las empresas competitivas son aquellas que despliegan capacidades únicas, diferente a la mayoría de empresas que desarrollan capacidades genéricas.

\subsubsection{Capacidades genéricas objeto de estudio}

Capacidades Directivas: Las capacidades directivas están relacionadas con el capital humano, sus conocimientos, habilidades y actitudes, como recurso de mayor potencial en la generación de ventajas competitivas. Las capacidades son únicas en las personas, por ende, la imitación de una ventaja competitiva es difícil, constituyendo como estrategia competitiva construir, mejorar y acumular recurso humano. 
Capacidades de Innovación y desempeño: El conocimiento tecnológico y la capacidad para generar innovación, constituye una fuente crítica de ventaja competitiva.

La innovación es la introducción y/o mejoramiento de un nuevo producto o servicio, se deriva de la competitividad a largo plazo, dando la posibilidad de crear a menos coste y más rápidamente que los competidores, tecnologías y habilidades esenciales den lugar a productos absolutamente innovadores, apunta la importancia de esta perspectiva más apropiada para analizar el efecto mutuo.

Capacidades de Marketing y desempeño: Las capacidades de marketing están relacionadas a la generación de valor para el cliente entendido como la evaluación global de la utilidad de un producto basándose en la percepción de lo que este recibe y da.

Capacidades de calidad y desempeño: La calidad definida como el logro de la conformidad o adecuación del conjunto de características y atributos de un producto o servicio con las expectativas y necesidades del cliente, es un factor decisivo en la competitividad de una organización.

\subsection{COMPETITIVIDAD SISTÉMICA}

La competitividad sistémica, es un modelo teórico formulado por un grupo de investigadores del Instituto Alemán del Desarrollo (Klaus Esser, Wolfgang Hillebrand, DirkMessner, Jörg Meyer-Stamer), surge como una herramienta teórica necesaria ante los niveles de complejidad alcanzados por la propia sociedad en la era de la globalización y cambio tecnológico. La competitividad sistémica tiene como premisa la integración social, propone no solo reformas económicas, sino también un proyecto de transformación de la sociedad. (Hernández, 2006) El concepto de competitividad sistémica enfatiza los siguientes aspectos: La competitividad de la economía se basa en medidas engranadas entre sí, apuntan a objetivos concretos desde cuatro niveles del sistema (meta, macro, micro y meso). Por otra parte, la competitividad sistémica, hace referencia a un concepto pluridimensional de conducción que se compone de competencia, dialogo y toma conjunta de decisiones que incluye a los grupos importantes de actores. (Klaus, 1994)

\subsubsection{Niveles de análisis de la competitividad}

a) Nivel meta: En este nivel se analiza integralmente la capacidad de los agentes de orden local, regional y nacional, a fin de establecer condiciones favorables para el desarrollo económico y social (Hernández, 2006). Desde esta perspectiva, la competitividad sistémica tiene como premisa la integración social, basada en la exigencia no solo de reformas económicas, sino también de la necesidad de transformación de la sociedad (Klaus, 1994). Por tanto es importante desarrollar estructuras sociales modernas conducentes a generar progreso permanente de las capacidades creativas de la sociedad, y a la vez fortalecer la comunicación entre las diferentes organizaciones e instituciones del entorno meta económico (Molina, 2011). Por otra parte, es necesario que los países en desarrollo asuman la tarea de superar la fragmentación social, mejorar la capacidad de aprendizaje y transferencia del mismo y ante todo fortalecer la capacidad para responder con prontitud y eficacia a los requerimientos de ajuste (Klaus Esser, 1994). 
b) Nivel macro: Este nivel hace referencia a la generación de un ambiente económico estable, para que los países se inserten en los mecanismos complejos de la competitividad internacional. Hacen parte de este nivel elementos de carácter macroeconómico (déficit fiscal, inflación, tipo de cambio y tasa de interés). Además influyen aspectos externos como precios internacionales y exigencias de calidad de los mercados (gustos y preferencias, segmentación, volumen y tendencia de los factores de la demanda). A este nivel las políticas presupuestaria, monetaria, fiscal, cambiaria y comercial juegan un papel clave en el apoyo a la competitividad).

c) Nivel meso: Para comprender mejor la dimensión del nivel meso en la competitividad sistémica, es conveniente resaltar "Las empresas que compiten en el mercado mundial, ya no son empresas aisladas que operan de forma descentralizada, sino clústeres industriales, grupos de empresas constituidas en redes, cuya dinámica de desarrollo depende de la eficacia de sus localizaciones industriales, es decir de la existencia de universidades, centros de entrenamiento, centros de ID, sistemas de información tecnológica, organizaciones sectoriales privada y muchas entidades más" (Klaus, 1994).

En este nivel se destacan los factores de carácter espacial (localización), de infraestructura y logística, calidad y cantidad de recursos naturales y factores climáticos. Así mismo destaca la presencia de las políticas de corte regional relacionadas con dichos factores, tales como la política de ciencia y tecnología, de infraestructura y equipamiento, ambiental e incluso las relacionadas con el comercio, básicamente las referidas al apoyo en exportaciones e importaciones.

d) Nivel micro: La competitividad micro económica, constituye el punto de partida de la competitividad sistémica. Las empresas se ven confrontadas hoy con requerimientos cada vez más fuertes que resultan de distintas tendencias.

En este nivel hace parte los factores que condicionan el comportamiento de la empresa tales como productividad, costos, organización, innovación y tecnología, control de calidad, gestión y logística empresarial, mecanismos de comercialización, tamaño de la empresa y distancia entre ésta, sus fuentes de insumo

\section{Tendencias competitivas del transporte de pasajeros}

\subsection{Tendencias competitivas a nivel mundial}

Las tendencias de competitividad en el transporte a nivel mundial, en la actualidad, giran en torno a la implantación de políticas integradas de transporte sostenible, limpio y energéticamente eficiente, a razón de diversos cambios en la sociedad, como el aumento de la población mundial, que pasó de 2500 millones de habitantes en 1950, 6000 millones de habitantes en el año 2000, más de 7000 millones de habitantes en el 2013 y se espera que al finalizar el siglo XXI, la población mundial llegue cerca de los 11.000 millones de habitantes (Departamento de Asuntos Económicos y Sociales de la ONU (DESA), 3 de Mayo de 2011). Ante este tipo de situaciones Wolfang Meyer, Presidente de la UITP5 ${ }^{5}$, en el Congreso celebrado en

5 UITP, fundada en 1885, es la organización internacional que reúne las autoridades del sector transporte público, los operadores, los grupos de toma de decisiones, las organizaciones científicas, 
Madrid en 2005, afirma "El transporte público en el mundo se encuentra en un momento crucial de su desarrollo, con tendencias de gran magnitud como son el crecimiento urbano, los cambios demográficos y de estilo de vida, la globalización de la economía y el acceso generalizado a nuevas tecnologías que afectan cada vez más a nuestro sector. Ahora es cuando debemos ser proactivos e identificar una serie de soluciones específicas a fin de que el sector tenga las armas para afrontar de manera efectiva estos retos en el futuro.....Finalmente concluye que siendo el sector transporte crítico en cuanto a los futuros avances económicos, sociales y medioambientales, es deber de todos los gobiernos y empresas de todos los sectores involucrado, comprometerse a seguir políticas y programas destinados a mejorar las tendencias actuales de movilidad y cambiar radicalmente nuestros hábitos actuales de consumo y producción...

\subsection{LÍNEAS DE ACCIÓN DE COMPETITIVIDAD EN EL TRANSPORTE}

La UITP, plantea 3 grandes líneas de acción con el fin de proponer un transporte urbano o regional sostenible y de calidad. Los parámetros son los siguientes (Colmenares, 2007):

1. Equidad Social: El transporte de pasajeros debe conducir a la equidad, muchas personas sin distinción alguna, hacen uso de este servicio, por comodidad, seguridad, economía entre otros factores. Por tanto el desarrollo de la red vial, no constituye en sí la respuesta adecuada a la mejora del servicio, debido a que en las grandes ciudades del mundo, es evidente la congestión de las vías. La tendencia indica que se deben desarrollar sistemas que puedan transportar un elevado número de personas como los tipo metro, trenes ligeros, trolebuses, autobuses y ahora los metro cables, siempre circulando en vías exclusivas.

2. Equilibrio Medioambiental: El transporte es uno de los mayores consumidores de energía y todavía depende en gran medida de los carburantes fósiles no renovables. Según un estudio realizado por la Agencia Internacional de Energía, AIE en 2020 el sector del transporte será el mayor consumidor de energía por delante de la industria

3. Valor económico: El transporte constituye una herramienta eficaz para el desarrollo social de las comunidades, convirtiéndose en el eje articulador de la productividad y la competitividad, debido a la importancia de las operaciones logísticas de las organizaciones, por tal motivo, todos los esfuerzos deben apuntar a garantizar calidad tanto en términos de movilidad, comodidad, seguridad y accesibilidad.

\subsection{Tendencias competitivas a nivel nacional}

\subsubsection{Régimen jurídico del transporte de pasajeros por carretera en Colombia.}

Según estudio de caracterización del transporte en Colombia realizado en el año 2005, por el Ministerio de Transporte, la prestación del servicio de transporte público de pasajeros, que constitucionalmente es inherente a la finalidad social del estado, ha sido delegada por éste en los particulares, mediante un ejercicio

los proveedores de equipos y los industriales. Es una plataforma para la cooperación mundial y para el intercambio del conocimiento entre 2.500 miembros y 80 países. 
de intervención en la operación a través de la regulación, control y vigilancia con el fin de asegurar una adecuada prestación en términos de calidad, seguridad y eficiencia(Ministerio de Transporte de Colombia, 2005). Para el cumplimiento de la regulación el sector de transporte de pasajeros cuenta con un conjunto de normas, que permiten establecer las políticas de prestación del servicio:

Tabla 1 Normatividad relacionada con la prestación del servicio de transporte de pasajeros en Colombia

\begin{tabular}{|c|c|}
\hline DECRETO O LEY & OBJETO \\
\hline Decreto 171 de 2001 & $\begin{array}{l}\text { Reglamenta la habilitación de las empresas de Transporte } \\
\text { Público Terrestre Automotor de Pasajeros por Carretera y } \\
\text { la prestación por parte de estas de un servicio eficiente, } \\
\text { seguro, oportuno y económico, bajo los criterios básicos } \\
\text { de cumplimiento de los principios rectores del transporte. } \\
\text { (Ministerio de Transporte de Colombia, 2001) }\end{array}$ \\
\hline $\begin{array}{l}\text { Decreto } 1485 \text { de } \\
2002\end{array}$ & $\begin{array}{l}\text { Reglamenta EI Fondo Nacional de Reposición y Renovación } \\
\text { del Parque Automotor de Servicio Público de Transporte } \\
\text { Terrestre de Pasajeros.(Ministerio de Transporte de Colombia, } \\
\text { 2002) }\end{array}$ \\
\hline $\begin{array}{l}\text { Decreto número } \\
0491 \text { de } 1996\end{array}$ & $\begin{array}{l}\text { Se establecen condiciones técnicas del servicio de } \\
\text { transporte terrestre de pasajeros. Las condiciones son: } \\
\text { Homologación automática, revisión técnico mecánica, } \\
\text { licencias de conducción y certificado de movilización } \\
\text { (Ministerio de Transporte de Colombia, 1996) }\end{array}$ \\
\hline $\begin{array}{l}\text { Documento Conpes } \\
3260 \text { de } 2003\end{array}$ & $\begin{array}{l}\text { Se presenta la política del Gobierno Nacional para impulsar } \\
\text { la implantación de sistemas integrados de transporte masivo } \\
\text {-SITM- en las grandes ciudades del país y fortalecer la } \\
\text { capacidad institucional para planear y gestionar el tráfico y } \\
\text { transporte. (Departamento Nacional de Planeación, 2003) }\end{array}$ \\
\hline $\begin{array}{l}\text { Resolución } 7811 \text { de } \\
2001\end{array}$ & $\begin{array}{l}\text { Se establece libertad tarifaria para la prestación de servicio } \\
\text { público de transporte terrestre intermunicipal de pasajeros } \\
\text { por carretera. (Ministerio de Transporte de Colombia, 2001) }\end{array}$ \\
\hline $\begin{array}{l}\text { Resolución } 3600 \text { de } \\
2001\end{array}$ & $\begin{array}{l}\text { Se fijan las tarifas mínimas para la prestación del servicio } \\
\text { público de transporte terrestre automotor de pasajeros por } \\
\text { carretera (Ministerio de Transporte de Colombia, 2001) }\end{array}$ \\
\hline
\end{tabular}

Gallo (2012) hace una síntesis de los últimos avances en materia de transporte de pasajeros, lo cual refleja claramente las tendencias innovadoras de algunas de las empresas más representativas del país. Una de estas organizaciones invirtió en vehículos innovadores 19.000 millones de pesos en un año, además el sector 
transporte terrestre de pasajeros viene implementado soluciones tecnológicas de seguimiento que mejoran la seguridad y confiabilidad del servicio. Ejemplo de ello, es la ventaja tecnológica en el servicio que permite a un familiar de un pasajero consultar en tiempo real ingresando a la página web de la empresa de transporte en qué lugar del camino se encuentra el pasajero, la velocidad a que avanza el bus y la hora a la que llegará a la ciudad de destino. Según la Cámara Sectorial de Transporte de la ANDI, 519 empresas conforman el sector transporte terrestre de pasajeros (de las cuales el $57 \%$ son sociedades comerciales y el $43 \%$ pertenecen al sector cooperativo) acceden al mercado a través de un permiso de operación que concede el Ministerio de Transporte para prestar el servicio en una ruta determinada, por término indefinido y bajo un régimen de libertad tarifaria con precios mínimos establecidos periódicamente por el Ministerio de Transporte. Cundinamarca es el departamento con mayor número de empresas (163), incluido Bogotá. Antioquia representa el $15.2 \%$ de las empresas del país. Las empresas de transporte habilitadas bajo la modalidad de servicio intermunicipal son vigiladas subjetiva y objetivamente por la Superintendencia de Puertos y Transporte, su actividad se encuentra regulada por los postulados generales de la Ley 105 de 1993 y Ley 336 de 1996. Los requisitos de acceso al servicio y operación han sido definidos en el Decreto 171 de 2001.La flota vehicular de transporte intermunicipal es de 38.882 vehículos, de los cuales el $48 \%$ corresponde a autobuses con capacidad para 32 o más pasajeros. En 2011 se movilizaron 126.338 .107 pasajeros en 12.798 .114 frecuencias (Cámara Sectorial de Transporte ANDI, 2012).

\subsubsection{Empresas innovadoras}

A) Expreso Bolivariano: Empresarios del transporte de pasajeros por carretera en Colombia están asumiendo el reto de prestar servicios de transporte de calidad e innovación. Para demostrar lo anterior, se tiene como ejemplo Expreso Bolivariano que modernizó su flota con la denominada '2G Golden' que consiste en buses con centros de entretenimiento. Según Juan Carlos Calderón, gerente de la empresa, tienen consolas individuales para ver películas, escuchar música o conectar computadores portátiles mediante los cuales el viajero, además, podrá conectarse a internet vía WiFi. En total, la empresa adquirió 40 buses de este tipo, cuyo costo individual es de 450 millones de pesos y se espera que ingresen otros 30 vehículos. De igual forma Expreso Bolivariano también realizó una inversión en infraestructura tecnológica que le permite al pasajero, al igual que en una aerolínea, comprar el pasaje para cualquier época del año y seleccionar su lugar preferido en el bus a través del sitio en internet o por plataformas como Vía Baloto o Envía, es decir, la misma figura del tiquete electrónico (Gallo, 2012)

B) Expreso Brasilia: Mario Rodríguez Escallón, presidente de Expreso Brasilia, otra de las grandes compañías del país, dice que en vez de disminuir, está aumentando el flujo de pasajeros. En su caso, el aumento es del 12 por ciento en lo que va del año. La compañía espera tener en su parque automotor buses de dos pisos para los principales destinos. Adicionalmente, 60 buses nuevos ingresaron a la flota que tendrán internet y pantallas de entretenimiento. Las inversiones serán superiores a los 20 mil millones de pesos.(Gallo Machado, 2012). Expreso Brasilia, ofrece un conjunto de servicios que permiten al pasajero Comprar tiquetes en más de 70 destinos nacionales y Venezuela, comprar el tiquete en cualquiera de las agencias, para que este sea reclamado en otra agencia por otro usuario y hacer reservas para viajes por vía telefónica (Expreso Brasilia S.A, 2012).

C) Rápido Ochoa: Otra de las empresas competitivas a nivel nacional es Rápido Ochoa, que tiene una flota de 100 buses modernos para trayectos largos. Oscar Echeverri, gerente de la empresa, coincide en que la estrategia para sobrevivir en 
la dura competencia es llegar a ciudades intermedias a las que el avión no llega. Y como sus colegas lo han venido haciendo, en Rápido Ochoa también se están realizando inversiones para tener buses de última tecnología (internet inalámbrico, entretenimiento, espacio, servicio y vehículos de dos pisos), que tienen un costo individual de unos 700 millones de pesos (Gallo, 2012).

\subsection{Competitividad del transporte en Boyacá}

En el año 2004, Marco Julio Piragauta Plazas y Freddy Antonio Torres Amaya, del grupo de investigación permanente del Observatorio Regional de Gestión Empresarial Mi pyme en convenio UPTC - Cámara de Comercio de Tunja, realizaron una investigación dirigida a evaluar la gestión de la innovación en la pequeña empresa del sector transporte de Boyacá. El objetivo general de la investigación radica en conocer y evaluar los elementos, conceptos y argumentos que utiliza actualmente en la gestión, la innovación, la creatividad y el mejoramiento continuo de los empresarios del sector transportador en el departamento de Boyacá.

Los resultados más relevantes de la investigación realizada por Marco Piragauta y Freddy Torres son:

Los gerentes en su mayoría no son conscientes de la importancia de una gestión innovadora para lograr competitividad en el mercado, centran sus expectativas en tener mejor posicionamiento en el mercado, ya que aproximadamente el $50 \%$ de los encuestados, se inclinan por la anterior opción.

No se gestionan proyectos innovadores que le representen ventajas competitivas a las empresas, ya que aproximadamente 4 de cada 10 planes o proyectos, corresponden a pequeñas mejoras en procesos administrativos, 2 de cada 10 corresponden a pequeñas mejoras en procesos administrativos.

Se tiene como prioridad el servicio al cliente, teniendo este aspecto como lo más importante en la gestión empresarial para competir en el mercado, seguido de la innovación para asegurar ser competitivos. Sin embargo no se evidencia la ejecución de cambios que constituyan mejoras importantes al servicio al cliente.

Existe un desconocimiento del medio externo, por lo que ignoran las acciones innovadoras que se presentan, se refleja en que aproximadamente 6 de cada 10 empresas en Boyacá, no conocen actividades innovadoras realizadas por la competencia y no consideran este fenómeno como una amenaza para su estabilidad y posicionamiento en el mercado.

- Existe un estilo de gerencia tradicionalista, donde no se tiene en cuenta la innovación empresarial como estrategia importante para generar ventajas competitivas, dado que aproximadamente 5 de cada 10 empresas tienen como estrategia la eficiencia y la calidad en el servicio al cliente, sin ejecutar acciones trascendentales para implementar mejoras en este aspecto.

- No existe una estrategia definida para competir puesto que se presenta un desconocimiento en cuanto a la generación de ventajas competitivas en la gestión empresarial y una falta de proyección hacia el futuro. Lo anterior se refleja en que los proyectos ejecutados corresponden a actividades logísticas en un $22 \%$ y optimización del parque automotor en un $20 \%$.

- Se presenta una tendencia hacia la capacitación del personal en servicio al 
cliente. Aproximadamente 4 de cada 10 programas están enfocados hacia este fin; mientras la capacitación relacionada con la gestión de la innovación, solo se presenta en aproximadamente 1 de cada 10 programas; justificando así, su prioridad en la gestión empresarial, dando como resultado un bajo nivel competitivo, dado que no se ejecutan proyectos innovadores.

El reto del sector del transporte de pasajeros

Entidades como la Asociación Colombiana de Empresarios ANDI ${ }^{6}$, quienes monitorean continuamente la actividad empresarial en cada uno de los sectores de la economía nacional, afirmaron en el Tercer Congreso Nacional de Transporte de Pasajeros, llevado a cabo en Bogotá durante los días 12 y 13 septiembre de 2012: "La nueva política de transporte de pasajeros formulada por el gobierno nacional para la formalización y transformación de las empresas de transporte demanda de empresarios y de autoridades para generar espacios de estudio y construcción de las estrategias que hagan posible la modernización y competitividad del sector". Por tanto, se hace necesario conocer las principales dificultades del sector transporte de pasajeros, a fin de desarrollar proyectos conducentes a mejorar la competitividad y productividad del sector, mediante la adopción de prácticas enfocadas en la calidad, un factor predominante en la formulación de políticas que rigen este sector. Es importante que los empresarios del transporte diseñen estrategias conducentes a mejorar los procesos y generar valor agregado al servicio que se ofrece. Esta recomendación corresponde a Viviana Jaramillo, directora de la Cámara de Transporte Terrestre de la ANDI.(Gallo, 2012).

Como una necesidad al desarrollo de sistemas de transportes amigables con el medio ambiente en el año 2003, se crea el documento Conpes el cual busca impulsar la implantación de sistemas integrados de transporte masivo -SITM- en las grandes ciudades del país y fortalecer la capacidad institucional para planear y gestionar el tráfico y transporte en las demás ciudades, con el propósito de incrementar su calidad de vida y productividad, e impulsar procesos integrales de desarrollo urbano, dentro de un marco de eficiencia fiscal que promueva nuevos espacios para la participación del sector privado en el desarrollo y operación del transporte urbano de pasajeros. Según el documento Conpes 3260, de persistir la situación actual del transporte público colectivo de pasajeros, sus deficiencias seguirán limitando los niveles de productividad urbana y de calidad de vida en las grandes ciudades. Por ello, el reto de las ciudades colombianas es reducir la tendencia a la utilización ineficiente del automóvil particular promoviendo que la movilidad de las personas se fundamente en la utilización de los vehículos de transporte público, y en los vehículos y modos de transporte no motorizados.

Lo anterior explica la implementación de Sistemas Integrados de Transporte en las grandes ciudades, como una alternativa limpia, que aporta al cuidado del medio ambiente, siguiendo una de las tendencias mundiales descritas por Wolfang Meyer (2003), Presidente de la UITP, en su documento que aborda las tres paradas del transporte (Equidad Social, Equilibrio medio ambiental y valor económico)

6 La ANDI es una agremiación sin ánimo de lucro, que tiene como objetivo difundir y propiciar los principios políticos, económicos y sociales de un sano sistema de libre empresa, está en permanente actualización sobre el acontecer de la actividad empresarial. Por tal razón organiza certámenes, seminarios, conferencias, congresos, talleres, grupos de trabajo, que aclaran, aportan, e impulsan el desarrollo del sector. 


\section{METODOLOGIA}

En el estudio de análisis de brechas competitivas del sector de transporte intermunicipal de pasajeros se encuestaron 20 empresas de las cuales el $35 \%$, son micro empresas, el 35\% pequeñas, el 15\% medianas y el 15\% grandes empresas.

Por otra parte, en relación al tipo de empresas los resultados arrojan que el $60 \%$ de las empresas son cooperativas, seguido de un 25\% sociedades anónimas, $10 \%$ sociedades limitadas y $5 \%$ sociedades unipersonales.

Figura 1. Tamaño de las empresas encuestadas

\section{Tamaño de las empresas encuestadas}
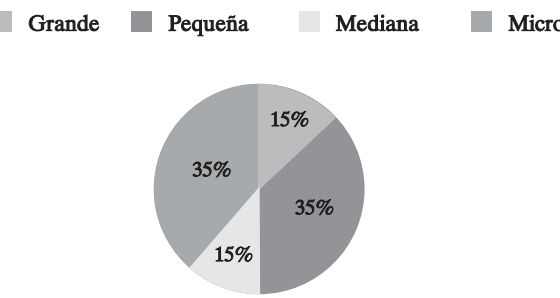

\section{Tipo de empresas encuestadas}

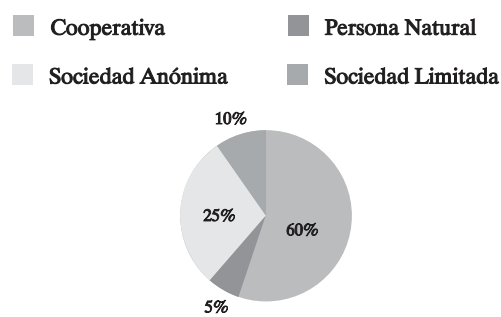

Fuente: Elaboración propia

\section{RESULTADOS}

\section{Resultados componente de calidad}

Parque automotor: Una de las variables más importantes en el análisis competitivo del sector del transporte intermunicipal de pasajeros está relacionada con la calidad del parque automotor, tal como lo menciona el artículo 26 del Decreto 171 de 2001"Los objetivos de calidad y excelencia estarán determinados por parámetros como la disminución de la edad del parque automotor, la optimización de los equipos de acuerdo con la demanda, la utilización de tecnologías limpias y otros parámetros que contribuyan a una mejora sustancial en la calidad y nivel de servicio inicialmente fijados"(Ministerio de Transporte de Colombia, 2001). Desde este punto de vista normativo, se infiere que una condición de sostenibilidad en el mercado está dada por la calidad de la infraestructura relacionada con la prestación del servicio de transporte, en este caso, los vehículos.

\section{a. Distribución del parque automotor por tipo de vehículo}

Con el fin de establecer parámetros de clasificación del parque automotor de las empresas y unificar criterios de agrupación de los vehículos, se tiene en cuenta el artículo 50 del Decreto 171 de 2001, el cual hace referencia a la racionalización en el uso de los equipos, la asignación de la clase de vehículo con la cual se prestara el servicio. De acuerdo a la capacidad de los vehículos el parque automotor se agrupa así: 
Tabla 2. Clasificación del Parque automotor

\begin{tabular}{|c|l|l|}
\hline GRUPO & \multicolumn{1}{|c|}{ CAPACIDAD } & \multicolumn{1}{|c|}{ UNIFICACIÓN } \\
\hline A & $4-9$ Pasajeros & $\begin{array}{l}\text { Automóvil, } \\
\text { camioneta } \\
\text { B }\end{array}$ \\
C & Más de 19 Pasajeros & Microbús \\
Buseta, bus \\
\hline
\end{tabular}

Fuente: Decreto 171 de 2001

Teniendo la clasificación del parque automotor del Ministerio de Transporte, se indagó a las empresas de transporte intermunicipal de pasajeros, a cerca de la distribución del parque automotor, representado en un total de 1505 vehículos de 20 empresas. Los resultados muestran que el $57 \%$ del total de los vehículos de las empresas encuestadas corresponden al grupo B, es decir a microbuses, seguido de un $22 \%$ del grupo C y $21 \%$ al Grupo B. Es de resaltar que solamente en el estudio se tienen en cuenta los vehículos que prestan el servicio de transporte intermunicipal, no se tiene en cuenta vehículos de servicio especial y servicio urbano.

b. Distribución del parque automotor por tipo de empresas según su tamaño: La distribución de la clase de vehiculos según el tamaño de las empresas, se muestra a continuación en la siguiente Figura comparativa.

Figura 2. Distribución del parque automotor por tipo de empresa según su tamaño

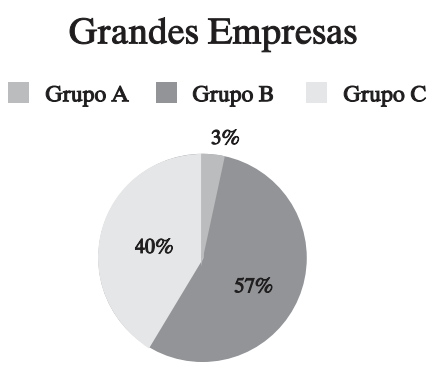

\section{Pequeñas Empresas}

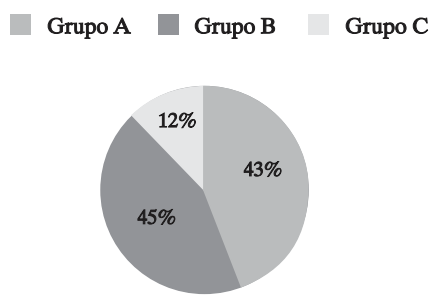

\section{Medianas Empresas}

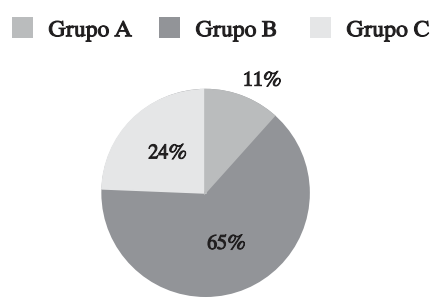

\section{Micro Empresas}

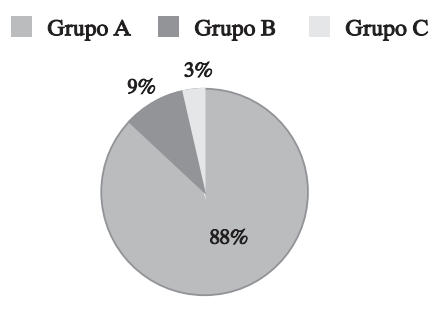

Fuente: Elaboración propia 


\section{Los resultados muestan:}

En las grandes empresas predominan los vehículos de grupo B en un 57\%, seguido del grupo C con el 40\% y 3\% grupo A.En las medianas empresas los vehiculos de mayor participación son los pertenecientes al grupo B con el 65\% una mayor proporción que en las grandes empresas, en un segundo lugar se encuentra el grupo C, con un $24 \%$ y el grupo A con el $11 \%$. En las pequeñas empresas el grupo más representativo de vehiculos es el B con el $45 \%$, seguido del grupo A con el $43 \%$ y por último el grupo $\mathrm{C}$ con el $12 \%$. En las micro empresas el $88 \%$ de los vehículos corresponden al grupo A, en menor proporción el grupo B (9\%) y grupo C (3\%).En las grandes y medianas empresas los vehículos del grupo B, son los más representativos; mientras en las empresas micros y pequeñas la tendencia está marcada hacia el grupo A.

c. Distribución del parque automotor por tipo de empresas según su naturaleza jurídica: La distribución de la clase de vehiculos según la naturaleza jurídica de las empresas, se muestra a continuación en la siguiente Figura comparativa.

Figura 3. Distribución del parque automotor según naturaleza jurídica de las empresas

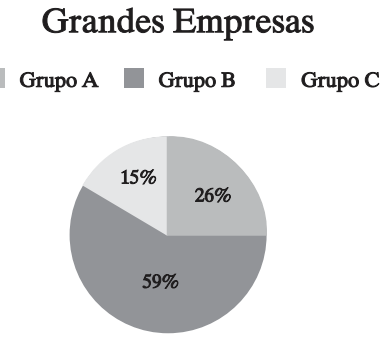

Pequeñas Empresas

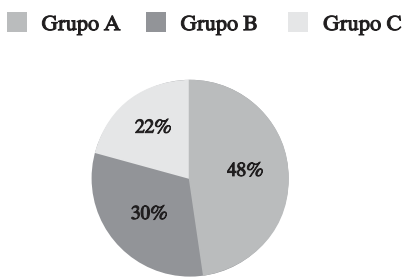

\section{Medianas Empresas}

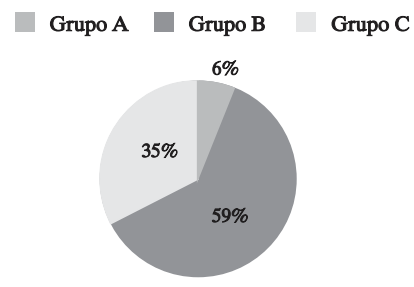

Micro Empresas

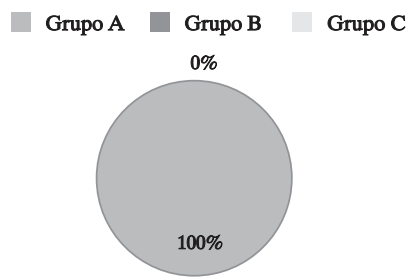

Fuente: Elaboración propia

\section{Los resultados muestan:}

En las cooperativas predominan los vehículos de grupo B en un 59\%, seguido del grupo A con el 26\% y $15 \%$ grupo C.En las sociedades anónimas los vehiculos de mayor participación son los pertenecientes al grupo B con el 59\% igual proporción que en las cooperativas, en un segundo lugar se encuentra el grupo $\mathrm{C}$, con un $35 \%$ y finalmente el grupo A con el $6 \%$.En las sociedades limitadas el grupo más representativo de vehiculos es el A con el $48 \%$, seguido del grupo B con el $30 \%$ y por último el grupo C con el $22 \%$. Se encuestó una empresa unipersonal en la que su 
parque automotor se clasifica totalmente en el grupo A

d. Distribución del parque automotor por Modelo: La distribución del parque automotor, teniendo en cuenta los modelos, se refiere la edad de los vehículos comprendida en el periodo 1980 a 2014. No se registran vehículos modelos anteriores a 1979 .

Según el estudio realizado las 20 empresas encuestadas cuentan con un parque automotor, de 1505 vehículos de los cuales el 46\% equivale a modelos comprendidos entre los años 2006 a 2010, el 19\% corresponde a vehículos de modelo 2001 a 2005, seguido de un 16\% que comprende modelos de los años 1991 a 2001 y el 6\% restante del parque automotor equivale a modelos de los 1980 a 1990.

Figura 4. Distribución del parque automotor por modelo

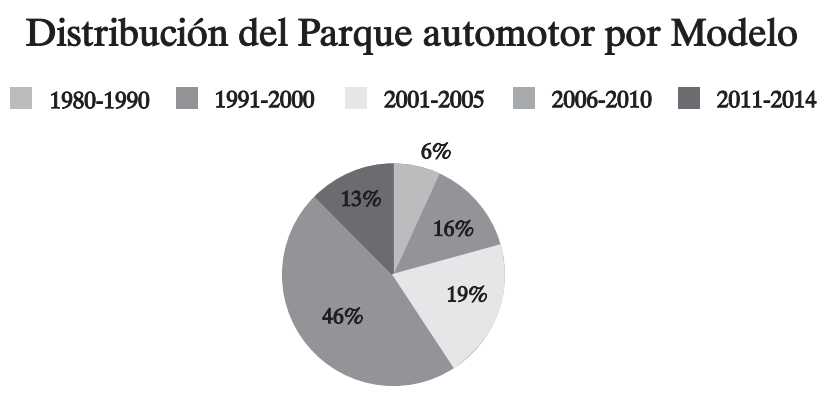

Fuente: Elaboración propia

1. Modelo del parque automotor por clase de empresa según su tamaño: La distribución del parque automotor po modelos por clase se empresa según el tamaño se presenta a continuación en la siguiente Figura: 
Figura 5. Modelo del parque automotor por clase de empresa según su tamaño

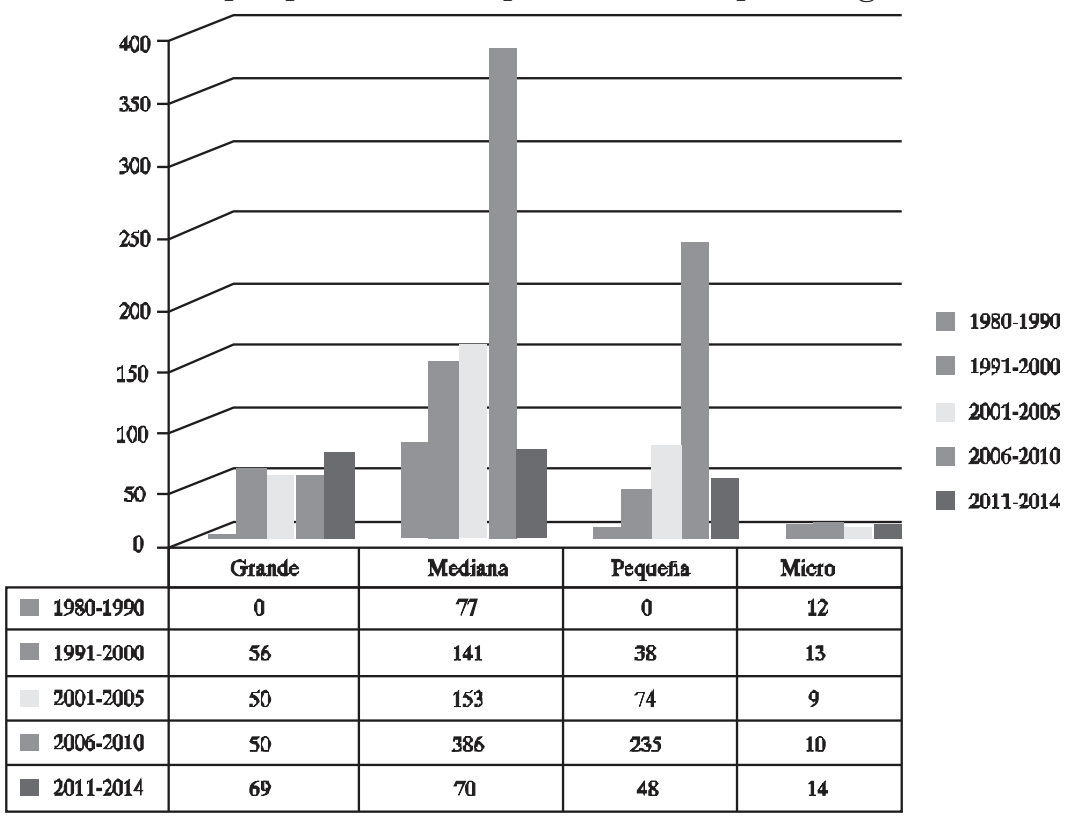

Fuente: Elaboración propia

El parque automotor de las empresas grandes encuestadas está conformado así: $25 \%$ de los vehiculos son de modelos comprendidos entre 1991 a 2000, $22 \%$ modelos comprendidos entre los años 2001 a 2005, 22\% modelos entre los años 2006 a 2010 y el $31 \%$ modelos de 2010 en adelalante.Con respecto al parque automotor de las empresas medianas, estas poseen el mayor número de vehículos con modelos comprendidos entre 1980 y 1990, los cuales corresponden al 9\% de los vehiculos de las empresas de este tamaño. El 17\% corresponde a modelos de los años 1991 a 2000, seguido de un 19\% correspondiente a vehiculos de modelos 2001 a 2005, el $47 \%$ de los vehiculos de este tipo de empresas son de modelo 2006 a 2010 y solo un $8 \%$ de los vehiculos con de modelos 2011 en adelante. En las empresas pequeñas el parque automotor está distribuido por modelos así: Modelos 1990 a 2000 10\%, modelos 2001 a 2005 19\%, modelos 2006 a 2010 59\% y modelos de 2011 en adelante $12 \%$.Por último en las microempresas el $21 \%$ de los vehiculos, son de modelos comprendidos entre 1980 y 1990, el $22 \%$ modelos entre 1991 a 2000 , el $16 \%$ modelos 2001 a 2005 , el $17 \%$ corresponde a modelos entre los años 2006 a 2010 y el 24 equivale a modelos de 2011 en adelante.

2. Modelo del parque automotor por clase de empresa según su naturaleza jurídica: El parque automotor de las cooperativas encuestadas está conformado así: 8\% de los vehículos son de modelos de los años 1980 a 1990,12\% de los vehiculos son de modelos comprendidos entre 1991 a 2000, 22\% modelos comprendidos entre los años 2001 a 2005, 45\% modelos entre los años 2006 a 2010 y el $13 \%$ modelos de 2010 en adelalante.

Con respecto al parque automotor de las sociedades anónimas, estas no poseen vehículos con modelos comprendidos entre 1980 y 1990. El 24\% corresponde a modelos de los años 1991 a 2000, seguido de un 13\% correspondiente a vehiculos 
de modelos 2001 a 2005, el $49 \%$ de los vehiculos de este tipo de empresas son de modelo 2006 a 2010 y solo un $14 \%$ de los vehiculos con de modelos 2011 en adelante.En las sociedades limitadas el parque automotor está distribuido por modelos así: Modelos 1980 a 1990 13\%, modelos 1991 a 2000 16\%, modelos 2001 a 2005 27\%, modelos 2006 a 2010 35\% y modelos de 2011 en adelante $10 \%$.En las 20 empresas encuestadas solo existe una empresa unipersonal, la cual posee en su totalidad vehículos de modelos comprendidos entre 2011 a 2014.

Factores de Calidad: Con relación a los factores de calidad incidentes en la prestación del servicio de transporte intermunicipal de pasajeros, se solicitó a los empresarios ennumerar las condiciones de calidad, con el fin de identificar su grado de importancia. Los resultados se describen en la siguiente tabla:

Tabla 3. Factores de calidad en la prestación de servicio de transporte intermunicipal de pasajeros

\begin{tabular}{|l|c|}
\hline \multicolumn{1}{|c|}{ Factor } & Ponderación \\
\hline Estado físico del vehículo & MUYALTO \\
\hline Trato al usuario & MUYALTO \\
\hline Presentación del conductor & ALTO \\
\hline Forma de operación del vehículo por parte de conductor & ALTO \\
\hline Tiempo de espera del pasajero en el vehículo & MEDIO \\
\hline Información de rutas y paradas & MEDIO \\
\hline Tarifa de transporte & BAJO \\
\hline Servicios adicionales & BAJO \\
\hline
\end{tabular}

Fuente: Elaboración propia

Se evidencia en la tabla anterior, que los factores más importantes en la prestación del servicio están relacionados con el estado físico del vehículo y el trato al usuario; la presentación del conductor y la forma de operación del vehículo, presentan una calificación alta; en término intermedio se encuentra, el tiempo de espera del pasajero en el vehículo e información de rutas y paradas. Por último la tarifa de transporte y los servicios adicionales al transporte de pasajeros, son los factores de menor importancia influyentes en la calidad del servicio.

Certificación de calidad: En relación con las normas de gestión de calidad, se indagó a los empresarios a cerca la certificación siguientes normas relacionadas con la prestación del servicio de transporte: 
COMPETITIVIDAD DEL SECTOR TRANSPORTE INTERMUNICIPAL DE PASAJEROS EN BOYACÁ

Tabla 4. Normas de certificación de calidad en el transporte terrestre de pasajeros

\begin{tabular}{|c|c|c|c|}
\hline NORMA & DESCRIPCIÓN & NORMA & DESCRIPCIÓN \\
\hline NTC 3641 & $\begin{array}{l}\text { Acabados interiores en } \\
\text { cuero }\end{array}$ & NTC 1256 & Uso de llantas \\
\hline NTC 1570 & \multirow{3}{*}{ Cinturones de seguridad } & NTC 1364 & \\
\hline NTC 2021 & & NTC 1467 & $\begin{array}{l}\text { Condiciones de los } \\
\text { vidrios }\end{array}$ \\
\hline NTC 2037 & & ISO 9001 & $\begin{array}{l}\text { Sistemas de gestión de } \\
\text { calidad }\end{array}$ \\
\hline NTC 3638 & Herrajes de silletería & ISO 14001 & $\begin{array}{l}\text { Sistemas de gestión } \\
\text { Ambiental }\end{array}$ \\
\hline NTC 3586 & $\begin{array}{l}\text { Materiales retardantes al } \\
\text { fuego }\end{array}$ & Otra & Otras normas \\
\hline
\end{tabular}

Fuente: Asociación Colombiana de Transporte Terrestre Automotor Especial, Acoltes 2008

Los resultados se muestran a continuación en la siguiente Figura:

Figura 6. Certificaciones en gestión de calidad

\section{Certificación en Gestión de Calidad}

$\square \mathrm{Si} \quad$ No $\quad$ En Proceso

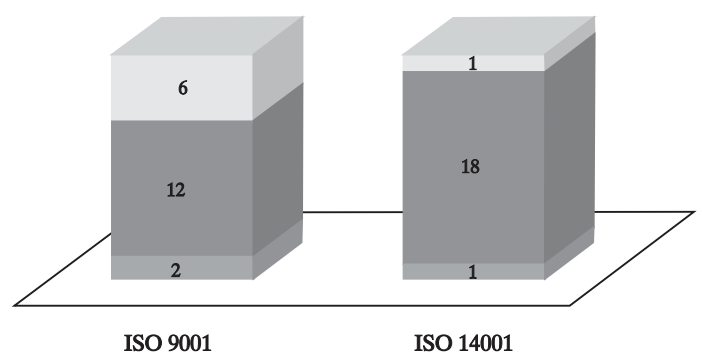

Fuente: Elaboración propia

Solo se obtiene información de la Norma ISO 9001, en gestión de calidad e ISO 14001 Gestión Ambiental, dando como resultado, una amplia brecha en procesos de certificación de calidad. Con relación a la norma ISO 9001 solo 2 empresas (grandes) de 20 encuestadas se encuetran certificadas, 6 en preceso de certificación y 12 no cuentan con ninguna norma. Con relación a la norma ISO 14001, solo una empresa se encuentra certificada en la norma, 1 e n proceso de certificación y 18 no han desarrollado gestión alguna para el proceso de certificación. 
Sobre las demás normas de certificación de calidad las cuales están relacionadas con las condiciones de los vehículos, en términos de seguridad y comodidad, no se obtuvo información ante el desconocimiento de los empresarios de dichas normas, manifiestan que estas son de más aplicación en el sector de fabricación de los vehículos, más no son aplicables en la prestación del servicio.

Motivos de no certificación de normas de gestión de calidad: Las empresas que manifestaron no contar con ninguna norma de gestión de calidad, exponen los motivos que han impedido la certificación en alguna de estas, los cuales se presentan en la siguiente tabla:

Tabla 5. Motivos de No Certificación en Normas de gestión de calidad

\begin{tabular}{|l|}
\hline \multicolumn{1}{|c|}{ MOTIVOS DE NO CERTIFICACION EN NORMAS DE GESTIONDE CALIDAD } \\
\hline Desconocimiento el proceso de certificación normas de gestión de calidad. \\
\hline Capacitación insuficiente \\
\hline Deficiente gestión por parte de los gerentes \\
\hline Sistemas de información deficientes \\
\hline Alta rotación de personal \\
\hline No es necesaria la certificación de calidad \\
\hline La calidad está definida por las normas del Ministerio de Transporte \\
\hline Por el tamaño de las empresas, no es necesario la certificación de calidad \\
Fuente: Elaboración propia
\end{tabular}

Estrategias de mejoramiento: Con relación a las estrategias de mejora continua de las empresas de transporte intermunicipal de pasajeros, el 31\% de las respuestas giran en torno a la renovación y mantenimiento del parque automotor. Las estrategias relacionadas con la atención al cliente ocupan el segundo lugar con el 29\%, seguido de la capacitación a conductores y personal influyente en la prestación con el 17\%. El mejoramiento continuo en todas las actividades empresariales representa el 14\% y por último el cumplimiento de la normatividad como estrategia de mejoramiento continuo con el $9 \%$. 
Figura 7. Estrategias de Mejora Continua

\section{Estrategia de mejora continua}

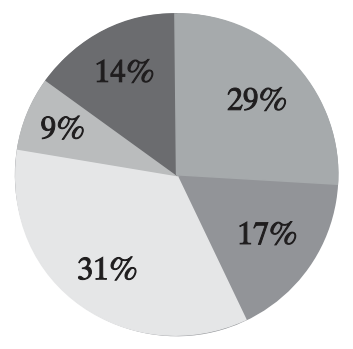

\section{Atención al cliente}

Capacitación

Renovación del parque automotor

Cumplimiento de normatividad

Mejoramiento continuo

Fuente: Elaboración propia

Registros de Calidad: Todas las empresas de transporte intermunicipal de pasajeros encuestadas manifestaron contar con registros ya sea documentos o programas de software que evidencian la calidad en la prestación del servicio. Los registros de calidad, se relacionan en la siguiente tabla:

Tabla 6. Registros de calidad

\begin{tabular}{|l|}
\hline \multicolumn{1}{|c|}{ REGISTROS DE CALIDAD EN EL TRANSPORTE DE PASAJEROS } \\
\hline Informes de operatividad \\
\hline Buzón de quejas y reclamos \\
\hline Fichas técnicas de operación \\
\hline Control de mantenimiento vehicular \\
\hline Mantenimiento preventivo \\
\hline Mantenimiento correctivo \\
\hline Pruebas de alcoholemia a conductores \\
\hline Hoja de vida vehicular \\
\hline Cuadro de rodamiento \\
\hline Registro revisión técnico mecánica \\
\hline Indices de operación (Indices de ocupación, accidentalidad y prestación del servicio) \\
\hline $\begin{array}{l}\text { Registro de trazabilidad del servicio (Mantenimiento vehicular - Llegada al destino de } \\
\text { viaje) }\end{array}$ \\
\hline
\end{tabular}

Fuente: Elaboración propia

Limitantes de la calidad: Los aspectos que limitan la prestación del servicio intermunicipal de pasajeros, con alta calidad son: En un 27 de las respuestas se encuentra la políticas públicas, seguido del $19 \%$ relacionado con la falta de recursos financieros que garanticen la calidad del servicio. El desconocimiento de la normatividad y/o las afectaciones negativas de la misma limitan la calidad en $19 \%$; por otra parte, el desconocimiento de las nuevas tecnologías en el servicio 
representa el $12 \%$ de las respuestas, en menor proporción, se encuentra la falta de un personal competente (11\%), falta de cultura organizacional (8\%) y el uso inadecuado y/o ausencia de sistemas de información (4\%)

Resultados componente de innovación

Componente diferenciador empresarial

El Manual de Oslo define la innovación como la concepción e implantación de cambios significativos en el producto, proceso marketing o la organización de la empresa con el propósito de mejorar los resultados. Los cambios innovadores se realizan mediante la aplicación de nuevos conocimientos y tecnologías que pueden desarrollar internamente, en colaboración externa o adquirida mediante servicios de asesoramiento o compra de tecnología (UNED, 2010). Desde este punto de vista, se indagó a los empresarios del transporte a cerca del componente diferenciador de la empresa en los siguientes factores:

Infraestructura: Equipos e instalaciones utilizados para prestación del servicio de transporte. Se incluye variables como edad y tamaño del parque automotor, clase de vehículo, unificación de marca, entre otros.

Servicio: Características únicas y rendimientos diferenciados del servicio ofrecido por la competencia.

Marketing: Métodos de comercialización del servicio, diferenciación en la forma de prestación del servicio, sistemas de tarifación, medios de promoción, cubrimiento en el mercado y portafolio de servicio.

Gestión organizacional: Diferenciación en prácticas y procedimientos de las decisiones empresariales, calidad de las relaciones exteriores, introducción de sistemas de gestión de las operaciones en la prestación del servicio y gestión de calidad.

- Componente diferenciador: Infraestructura.

La siguiente Figura, muestra los resultados de la diferenciación en relación al factor de infraestructura: 
Figura 8. Componente diferenciador Infraestructura

\title{
Componente diferenciador: Infraestructura
}

\author{
Parque automotor \\ Instalaciones para la prestación del servicio \\ No identifican componente diferenciador \\ Única empresa de la región
}

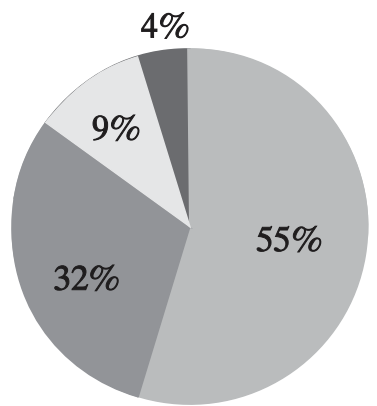

Fuente: Elaboración propia

Los empresarios encuestados consideran que el componente diferenciador en relación con la infraestructura del servicio, está relacionado con el parque automotor en un 55\%. Las respuestas encontradas en este ítem se describen en la siguiente Figura:

Figura 9. Componente diferenciador del parque automotor

\section{Diferenciación en el parque automotor}

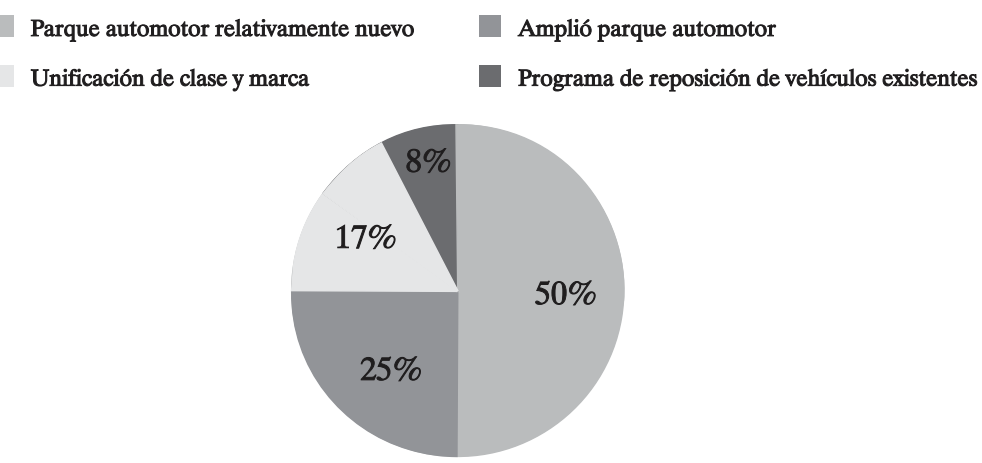

Fuente: Elaboración propia

El 50\% de las respuestas enfocadas hacia el parque automotor están relacionadas con la propiedad de vehículos relativamente nuevos, el $25 \%$ se orienta hacia el tamaño del parque automotor, seguido de un $17 \%$ que manifiestan que el componente 
diferenciador está dado por la unificación de marca y clase de vehículos y por último el 8\% apunta a programas de reposición de equipos.

En el segundo lugar del componente diferenciador de infraestructura, se encuentra la calidad de las instalaciones físicas para la prestación del servicio, el cual representa el 32\%. La disposición de sede administrativa propia, estaciones de servicio de combustible y parqueaderos sustentan esta respuesta.

El 9\% de las empresas encuestadas, no identifican el componente diferenciador en el factor de infraestructura, consideran que no hay una diferenciación en relación con equipos e instalaciones influyentes en la prestación del servicio.

Por último, 4\% de las empresas encuestadas, orientan su respuesta hacia la ausencia de competencia, es decir, son únicos en la región, donde prestan el servicio.

\section{- Componente diferenciador: Servicio}

Los componentes diferenciadores del factor servicio (relacionado con las características de prestación del servicio) se relacionan en un $28 \%$ en cubrimiento de rutas y horarios, en algunas empresas operan 24 horas y prestan el servicio en zonas rurales, el $24 \%$ de las respuestas se orientan a la atención al cliente, mediante la adopción de conductas de cortesía y amabilidad por parte de los actores involucrados en la prestación del servicio, así como la información oportuna en diferentes puntos a los largo del viaje. La calidad del servicio ocupa el tercer lugar con el $16 \%$, esta se refleja en el mantenimiento preventivo y correctivo de equipos, programas de reposición vehicular y capacitación al personal. La forma de operar el vehículo por parte de conductor representa el 12\%, la cual está en función del cumplimiento de las normas técnicas y de seguridad tendiente a disminuir los índices de accidentalidad y comparendos. El 12\% de las empresas encuestadas, no identifican el componente diferenciador en el factor de servicio, consideran que no hay una diferenciación en relación con la prestación del servicio de transporte intermunicipal de pasajeros. Por último la capacitación al personal en temas relacionados con la calidad del servicio, ocupa el 8\%. Ver Figura 15.

Figura 10. Componente diferenciador Servicio

\section{Componente diferenciador: Servicio}

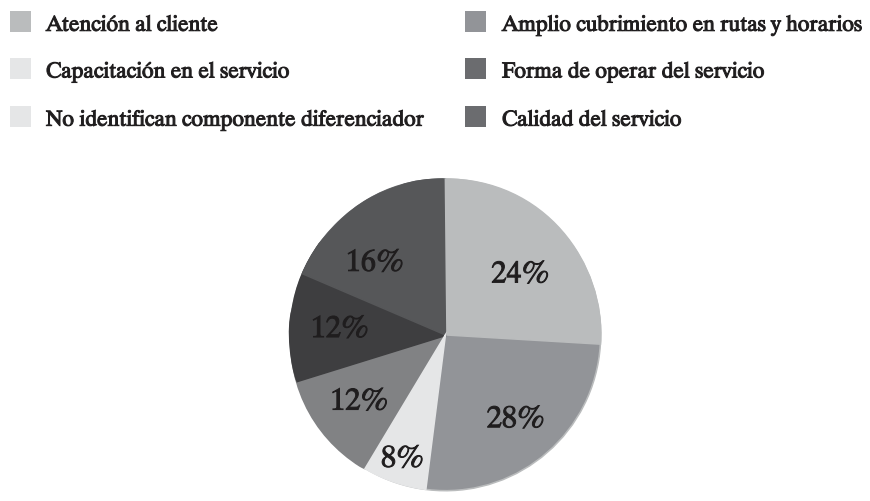

Fuente: Elaboración propia 


\section{- Componente diferenciador: Marketing.}

El componente diferenciador en el factor de marketing, (forma de comercialización del servicio) está orientado a la publicidad (38\%) como medio de promoción del servicio, mediante la pauta en medios publicitarios como radio y prensa, el uso de volantes, afiches publicitarios, así mismo, el patrocinio de eventos. En el segundo lugar se encuentra con un $29 \%$, las empresas que no identifican el componente de marketing, es decir, no hallan diferencia en el modo de comercialización del servicio con otras empresas del sector. Las relaciones humana como aspecto importante en la prestación del servicio, corresponde al 19\% de las respuestas dadas al factor marketing. En menor proporción, la información de rutas y horarios y la uniformidad de vehículos, representan el 9\% y 5\% respectivamente. Ver Figura No16.

Figura 11. Componente diferenciador Marketing

\section{Componente diferenciador: Gestión Organizacional}

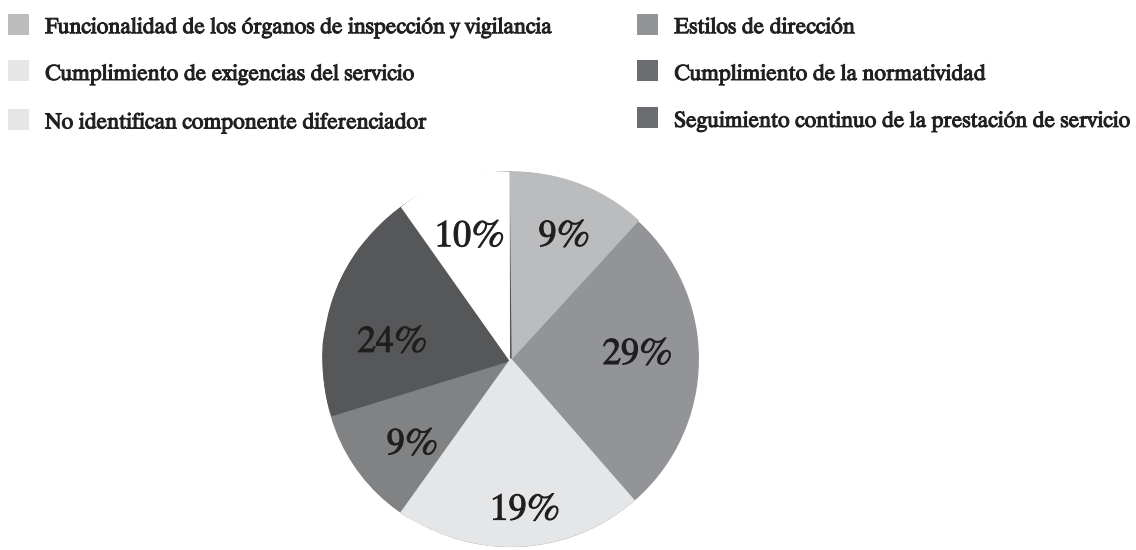

Fuente: Elaboración propia

\section{- Componente diferenciador: Gestión Organizacional}

El componente más representativo del factor gestión organizacional (diferenciación en prácticas y procedimientos de las decisiones empresariales) está relacionado con los estilos de dirección (29\%), orientados en los siguientes temas: Seguimiento diario en cuanto al estado del parque automotor, presentación y calidad del conductor, ordenamiento organizacional de competitividad frente a otras empresas, conocimiento integral de organizacional, capacitación de personal administrativo y operativo, innovación en estructura organizacional, vigilancia tecnológica y normativa, desarrollo de programas enfocados en el aumento del clima organizacional y desarrollo personal y profesional de empleados. El $24 \%$ de las empresas encuestadas no identifican el componente diferenciador del factor gestión organizacional, aducen razones de ausencia de conocimiento del funcionamiento administrativo y organizacional de la competencia. El 19\% se orienta hacia el cumplimiento de exigencia del servicio, indicador relevante en la función gerencial. En menor proporción se encuentran: Seguimiento continuo a la prestación del servicio (10\%), eficiencia de los entes internos de inspección y vigilancia y el 
cumplimiento de la normatividad, los dos últimos con el $9 \%$ respectivamente. Ver Figura No 17

Figura 12. Componente diferenciador Gestión Organizacional

\section{Componente diferenciador: Gestión Organizacional}

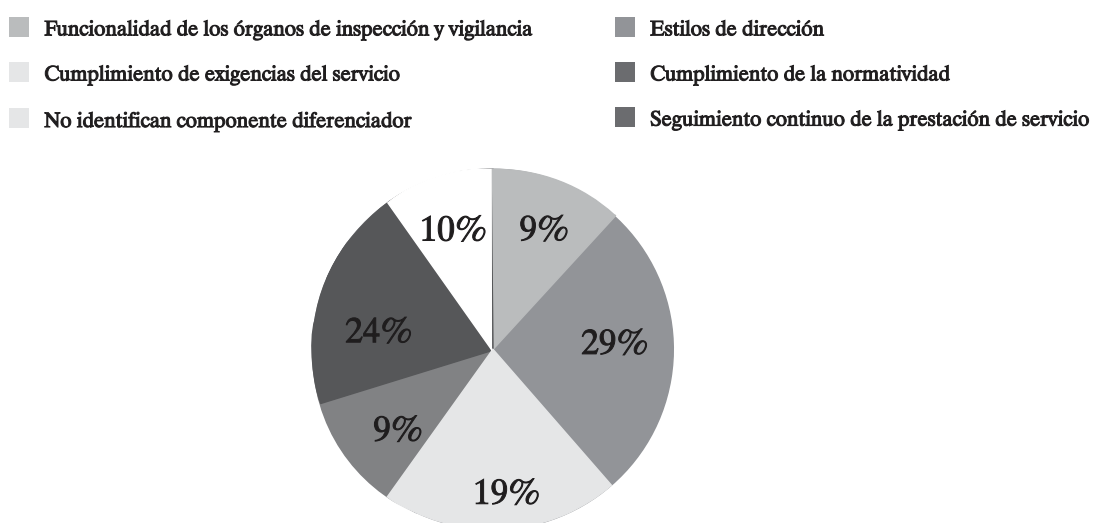

Fuente: Elaboración propia

\section{Ideas de mejoramiento para la diferenciación}

Las ideas de mejoramiento para la diferenciación en las diferentes áreas funcionales proceden en un $31 \%$ de las empresas, de la gerencia, seguido del $23 \%$ socios, accionistas o asociados dependiendo de la naturaleza jurídica organizacional. Las ideas de diferenciación surgen en un $18 \%$ de la junta directiva. Por otra parte los tesistas, aprendices, áreas de investigación desarrollo y el mercado, representan el $12 \%$, en menor proporción se encuentra usuarios, consejo de administración y pasantes, cada uno con el $4 \%$ respectivamente.

Figura 13. Procedencia de las ideas de mejoramiento para la diferenciación

Procedencia de las ideas de mejoramiento para la diferenciación
$\begin{array}{lll} & & \\ \text { Socios } & \text { Gerencia } & \text { Junta directiva } \\ \text { Trabajadores } & \text { Pasantes } & \text { Otross } \\ \text { Consejos de Administración } & \text { Usuarios } & \end{array}$

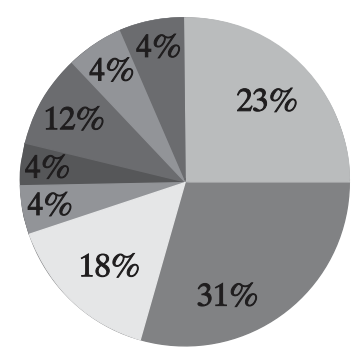

Fuente: Elaboración propia 


\section{Proyección empresarial}

Figura 14. Proyección empresarial del sector transporte intermunicipal de pasajeros

\section{Proyección empresarial}

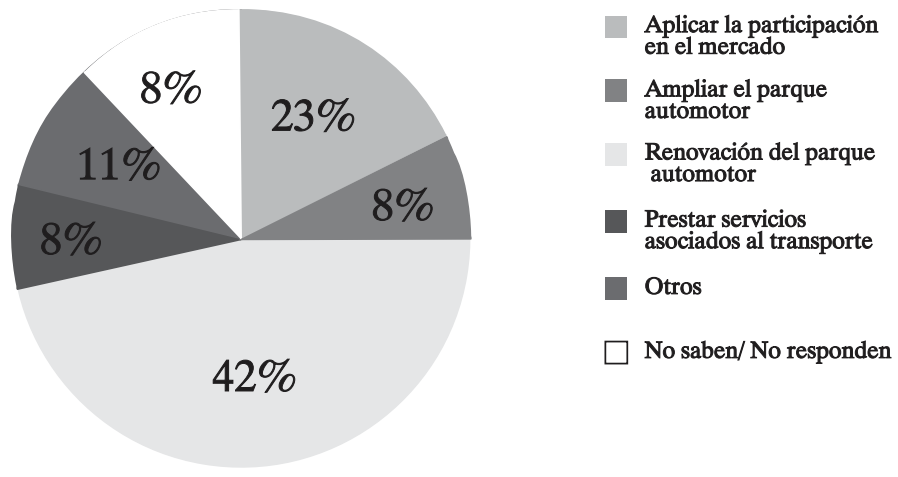

Fuente: Elaboración propia

Se preguntó a los empresarios del transporte intermunicipal de pasajeros, a cerca de la proyección empresarial a 3 años, los resultados apuntan en un $42 \%$ a la renovación del parque automotor, mediante la adquisición de vehículos nuevos de última tecnología. El 23\%, se orienta a ampliar la participación en el mercado mediante la asignación de nuevas rutas y horarios autorizados por el Ministerio de Transporte. El $11 \%$ de las respuestas corresponden a 3 ítems: Incremento de activos diferentes al parque automotor, aumento en el número de socios y el mejoramiento continuo mediante la adopción de sistemas de gestión de calidad. Por otra parte, el 8\% de las empresas considera que se proyecta con la prestación de nuevos servicios asociados al transporte como estaciones de servicio y centros de mantenimientos. Por último el $8 \%$ de los encuestados no saben o no responden a la pregunta. 


\section{Inversión en actividades de investigación y tecnología}

Figura 15. Inversión en actividades de investigación y tecnología

\section{Inversión de Actividades de Investigación y tecnología}

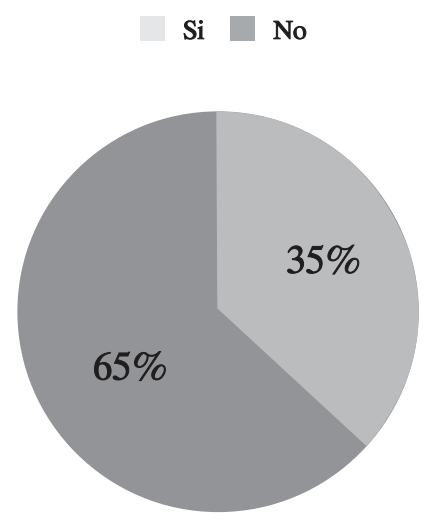

Fuente: Elaboración propia

El 65\% de las empresas encuestadas manifiesta no invertir en ninguna actividad de investigación y tecnología. El 35\%, equivalente a 7 empresas afirmaron invertir en las actividades mencionadas, específicamente en los siguientes temas: Tecnologías de la información y la comunicación (4), innovación en servicios (3) investigación y desarrollo (2), formación científica y tecnológica (2) y asimilación de nuevos conocimientos (1).

Figura 16. Actividades de investigación y tecnología

Actividades de investigación tecnológica

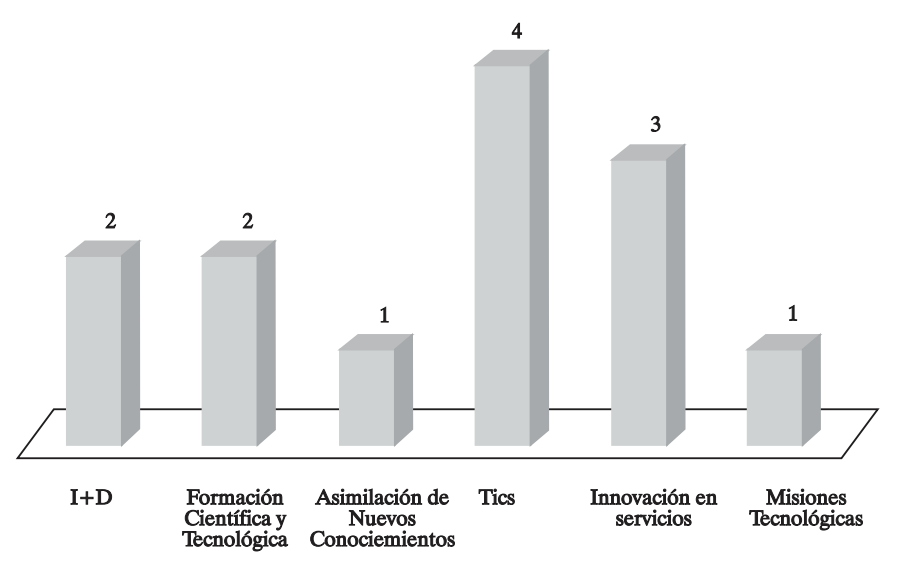

Fuente: Elaboración propia 


\section{Fuentes de financiación de innovación, investigación y tecnología.}

Las fuentes de financiación para el fomento de la innovación, investigación y tecnología son en su mayoría los recursos propios, que representa el $86 \%$ de las respuestas dadas por las empresas, mientras el $14 \%$ acuden a la banca privada para el financiamiento de estas actividades. Los recursos públicos no son opción de financiamiento para las empresas.

Figura 17. Fuentes de financiación de actividades de innovación, investigación y tecnología

Fuentes de financiación de actividades de innovación; investigación y tecnología

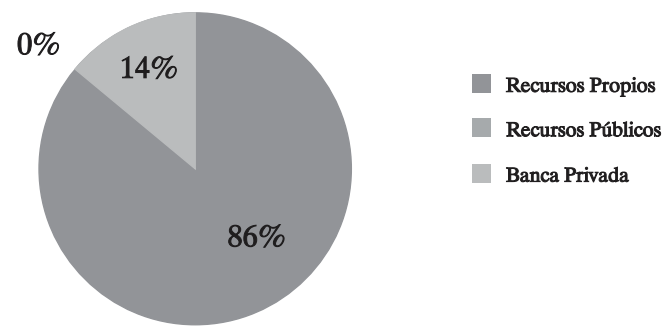

Fuente: Elaboración propia

\section{Uso de los sistemas de información}

Figura 18. Uso de sistemas de información

\section{Uso de sistemas de información}

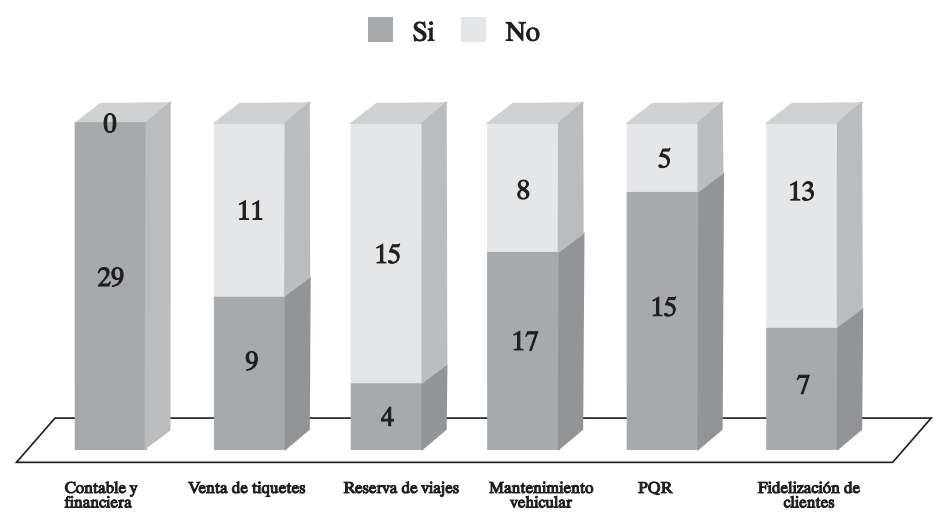

Fuente: Elaboración propia 
Con relación al uso de sistemas de información se observa en la anterior Figura: Todas las empresas encuestadas cuentan con sistema de información contable y financiera. Nueve empresas cuentan con sistema de venta de tiquetes. Las demás si bien no cuentan con el este sistema, hay algunas que se benefician por el sistema ATRA, ofrecido en las Terminales de transporte de Tunja, Duitama y Sogamoso. Solo 4 empresas cuentan sistemas de reserva de viajes. El mantenimiento vehicular cuenta con un sistema de información en 12 empresas. Quince empresas cuentan con el sistema de Preguntas Quejas y Reclamos PQR. Solo 7 empresas identifican sus clientes potenciales mediante un sistema de información.

\section{Resultados del componente de mercadeo}

\section{Medios de promoción}

Los medios de promoción del servicio de transporte intermunicipal de pasajeros, son en su orden: Radio (29\%), afiches publicitarios (21\%), prensa (16\%), página web (12\%), agencias de viaje (10\%), volantes (6\%) y otros medios como televisión, directorios telefónicos y vallas $(6 \%)$.

Figura 19. Medios de promoción

\section{Medios de promoción}

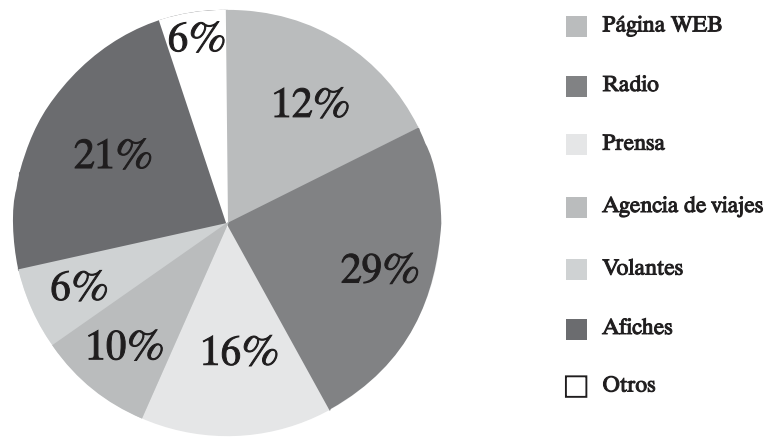

Fuente: Elaboración propia

Disposición de página web

Solo 6 empresas de las 20 encuestadas cuentan con página web, como medio de promoción organizacional, dentro de este grupo se encuentra 3 empresas grandes y 3 medianas. Los servicios que ofrecen las páginas Web de las 6 empresas que cuentan con esta herramienta, se muestran en la siguiente Figura: 
Figura 20. Servicios ofrecidos por las páginas web

\section{Servicio página WEB}

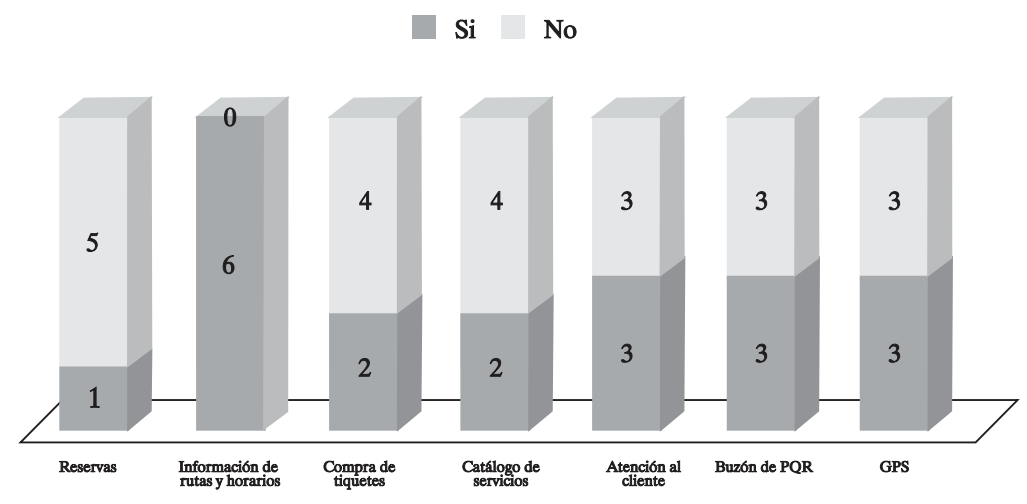

Fuente: Elaboración propia

Solo una empresa asegura disponer en su página web del servicio de reservación de tiquetes. Las 6 empresas dan a conocer por este medio información acerca de rutas y horarios. La compra de tiquetes según 2 empresarios se puede realizar virtualmente, en las páginas de sus empresas; sin embargo, una vez realizado el monitoreo en la red, se evidencia que este proceso aún no está disponible en ninguna empresa del sector en Boyacá. Los servicios de atención al cliente, buzón de quejas, preguntas y reclamos y el sistema de ubicación satelital GPS, se encuentra en 3 sitios web respectivamente.

\section{Medios de reservación}

Los medios más utilizados en la reservación de tiquetes de viajes son el teléfono fijo (32\%), el celular (30\%) y la reservación directa en la taquilla (29\%). Los medios menos utilizados son internet $(6 \%)$ y agencias de viaje $(3 \%)$

Figura 21. Medios de reservación

\section{Medios de reservación de tiquetes}

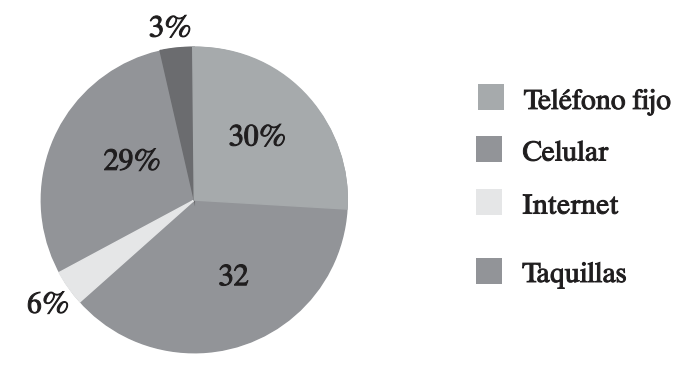

Fuente: Elaboración propia 


\section{Entorno empresarial competitivo}

\section{Reconocimiento empresarial}

Se preguntó a las empresas ¿Por qué consideran ser reconocidas en el entorno?. Las respuestas, se describen en el gráfico 34, el cual muestra la experiencia como el factor de mayor reconocimiento en el mercado ( 14 empresas). Diez empresas consideran ser reconocidas en el mercado, por la calidad, clase y tamaño del parque automotor. La imagen corporativa, como elemento calve en el posicionamiento de un producto o servicio en la mente consumidor en este caso, usuario del servicio, es un factor de posicionamiento empresarial para 8 empresas. Prestar servicios adicionales al transporte de pasajeros, como el envío de encomiendas y giros, es considerado por 6 empresas como un factor por el cual en el mercado son conocidos. Los aspectos menos importantes en el reconocimiento empresarial son: La tarifa y la innovación.

Figura 22. Reconocimiento empresarial

\section{Reconocimiento empresarial en el entorno}

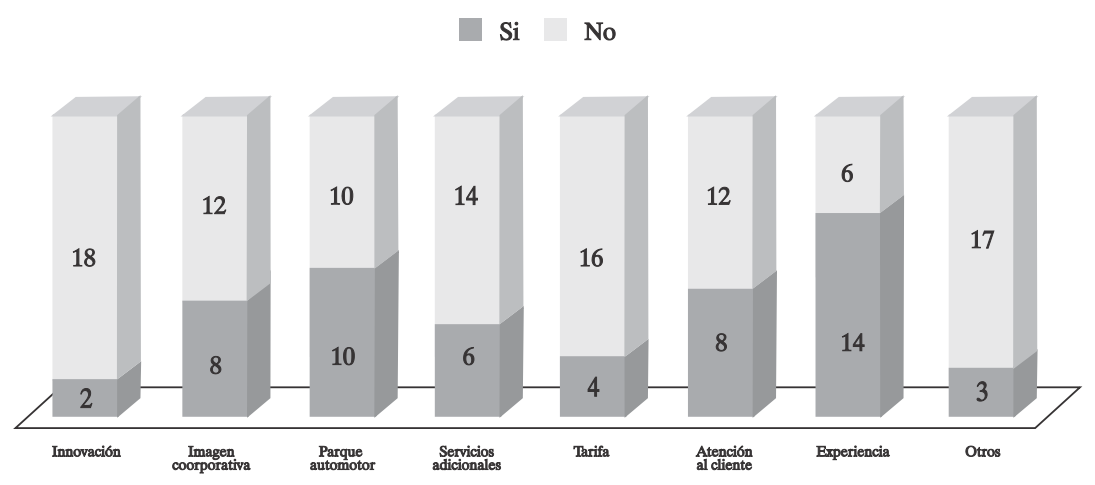

Fuente: Elaboración propia

\section{Relación con actores del entorno}

En general, los resultados del presente estudio, muestran una relación muy baja de las empresas de transporte intermunicipal de pasajeros en Boyacá con los actores del entorno. Los temas que más están trabando las empresas con los stakeholders son políticas y normatividad, con el Ministerio de Transporte y la Superintendencia de Transporte, seguido de las capacitaciones en diferentes áreas ofrecidas por el SENA. La asesoría contable y financiera, se trabaja en la mayoría de las empresas con asesores externos a las empresas, en algunos casos por contadores que hacen parte de la planta de personal administrativo. La transferencia de conocimiento es apoyada en 13 empresas por el SENA. Por último los temas que se les da menor importancia son diseño de nuevos servicios, investigación y desarrollo y nuevas alianzas entre empresas. A nivel general con las instituciones que más se tiene relación son el SENA y Ministerio de Transporte y las de menor grado de interacción están las alcaldías y la Gobernación.

\section{Impacto del entorno en la competitividad}

Con relación a las variables incidentes en la competitividad de las empresas de 
transporte intermunicipal de pasajeros, se solicitó a los empresarios ennumerar variables del entorno, con el fin de identificar su impacto sobre la competitividad del sector. Los resultados se describen en la siguiente tabla:

Tabla 7. Impacto de las variables del entorno en la competitividad

\begin{tabular}{|cc|}
\hline Variable & Impacto sobre la competitividad \\
\hline Mercado & ALTO \\
\hline Políticas & ALTO \\
\hline Competidores & MEDIO \\
\hline Infraestructura & MEDIO \\
\hline Proveedores & MUY BAJO \\
\hline
\end{tabular}

Fuente: Elaboración propia

Se observa que la variable más influyente sobre la competitividad de las empresas del sector, está relacionado con el mercado. Algunas de las empresas encuestadas opinan que el mercado se encuentra saturado por la débil regulación por parte de las entidades competentes, que permite la entrada de nuevas empresas, en muchas ocasiones reflejadas en la informalidad. Por otra parte, las políticas públicas también tienen una incidencia alta en la competitividad, debido a la normatividad emanada de los entes gubernamentales en diferentes sectores económicos que afectan la sostenibilidad de las empresas del sector. Los competidores tienen un impacto medio en la competitividad, debido a la ausencia de diferenciación en la prestación del servicio, es decir, son muy pocas las empresas del sector que innovan en la prestación del servicio. Por otra parte, la infraestructura, si bien, es un tema álgido en Colombia, a razón del precario estado de las vías, no constituye una variable de mayor incidencia en la competitividad, esto se debe a que una variable exógena a las empresas a la cual se deben ajustarse, es decir, la sostenibilidad del sector no debe estar en función de las condiciones de infraestructura de las vías. Por último los proveedores, tienen una incidencia mínima e la competitividad.

\section{CONCLUSIONES}

Actualmente los empresarios del transporte intermunicipal de pasajeros, ante los nuevos retos que implica la era de la globalización, deben asumir el reto del cambio que involucra acciones tendientes a garantizar un transporte moderno, ágil, seguro y cómodo.

El transporte constituye una herramienta eficaz para el desarrollo social de las comunidades, convirtiéndose en el eje articulador de la productividad y la competitividad, debido a la importancia de las operaciones logísticas de las organizaciones,

El transporte como motor de las economías, constituye una preocupación para los gobernantes en el ámbito nacional, departamental y municipal.

El entorno competitivo exige a los empresarios del sector de transporte de pasajeros y las entidades competentes, el diseño de estrategias conducentes a mejorar los procesos a fin elevar el valor del servicio que se presta.

El transporte público en el mundo se encuentra en un momento crucial de desarrollo, 
con tendencias de gran magnitud como son el crecimiento urbano, los cambios demográficos y de estilo de vida.

\section{REFERENCIAS BIBLIOGRÁFICAS}

Cámara Sectorial de Transporte ANDI. (2012). Transporte interurbano o intermunicipal de pasajeros. Transporte interurbano o intermunicipal depasajeros .

Colmenares, I. (2007). Desarrollo sustentable de sistemas de transporte público urbano. Impacto en la gerencia organizacional y liderazgo.

Departamento de Asuntos Económicos y Sociales de la ONU (DESA). (3 de Mayo de 2011). Centro de Noticias ONU.

Departamento Nacional de Planeación. (2003). Documento Conpes 3260 de 2003. Bogotá.

Expreso Brasilia S.A. (2012). Expreso Brasilia S.A. Recuperado el 4 de Julio de 2013, de Expreso Brasilia S.A: http:/www.expresobrasilia.com

Gallo, G. (26 de Agosto de 2012). El transporte terrestre pide pista en la guerra de tarifas aéreas. El Colombiano .

Gónzalez, M. (2000). Competitividad y estrategia: El enfoque de las competencias escenciales y el enfoque basado en los recursos. Revista Contaduría y Administración, p.p 47-63

Hernández, M. (29 de Octubre de 2006). La competitividad sistémica: Elemento fundamental de desarrollo regional y local. Ciencia y mar , 39-46.

Klaus, W. (1994). Competitividad sistémica. Berlín.

Martínez, J. (2010). Un modelo causal de competitividad empresarial, planteado desde la VBR: Capacidades direcitivas de innovación y marketing. Investigaciones Europeas de Dirección y Economía de la Empresa, 16 (2), 165-188.

Meyer, W. (2003). Billete al futuro: Las tres paradas de la movilidad sostenible. Bostón.

Ministerio de Transporte de Colombia. (2005), Caracterización del transporte en Colombia.

(2001) Decreto 171 de 2001.

(2002) Decreto 1482 de 2002.

(2006) Decreto 4688 de 2006

(1996) Decreto 0491 de 1996

(2001) Resolución 7811 de 2001

(2001) Resolución 3600 de 2001 
COMPETITIVIDAD DEL SECTOR TRANSPORTE INTERMUNICIPAL DE PASAJEROS EN BOYACÁ

Molina, C. (2011). Análisis de los efectos de la competitividad sistémica a nivel macro y meso. Colección Gestión, Emprendimiento e Innovación , 103.

Piñeiro, M., Jaffé, W. y Muller, G. (1993). Innovation, competitiveness and agroindustrial development. Presented at the meeting of integrating competitiveness sustainability and social development.

Piragauta, M. (2004). Evaluación de la gestión de innovación en la pequeña empresa de Boyacá - Sector Transporte. Tunja.

Porter, M. (2008). Las cinco fuerzas competitivas que le dan forma a la estrategia. Harvard Business Review América Latina , 18.

Uned. (2010). Resumen Manual de Oslo. 